\title{
Componentes de Carcaça e Composição de Alguns Cortes de Cordeiros Texel x Bergamácia, Texel x Santa Inês e Santa Inês Puros, Terminados em Confinamento, com Casca de Café como Parte da Dieta ${ }^{1}$
}

\author{
Iraides Ferreira Furusho-Garcia², Juan Ramón Olalquiaga Perez ${ }^{3}$, Júlio César Teixeira ${ }^{3}$
}

\begin{abstract}
RESUMO - Trinta e seis cordeiros, 12 cruzas Texel x Bergamácia (TB), 12 cruzas Texel x Santa Inês (TS) e 12 puros Santa Inês (SI), foram confinados individualmente, por um período de 50 dias. Cada grupo genético consistiu de seis machos inteiros e seis fêmeas, recebendo três diferentes dietas experimentais: 1 = sem casca de café (dieta controle); $2=$ com casca de café in natura; e 3 = com casca de café tratada com uréia e grão de soja moído. Os animais foram abatidos com idade média de 180 dias; posteriormente, foram avaliados os cortes da carcaça fria e a composição em músculo, osso e gordura da perna, paleta e do lombo. Para os outros cortes da carcaça e composição da perna, paleta e lombo, a utilização da casca de café, tratada ou não, não afetou os pesos. Os cordeiros SI mostraram menor peso para o músculo da perna e do lombo. O grupo genético não influenciou significativamente os pesos dos outros componentes, somente a paleta apresentou significância, indicando ser mais pesada para os animais TB e TS. Os machos apresentaram pesos maiores para braço posterior e anterior, pesos dos músculos da paleta, perna e lombo, e ainda, pesos maiores dos ossos da paleta e do lombo.
\end{abstract}

Palavras-chaves: ovinos, cruzamento, composição de carcaça, alimentação

\section{Carcass Components and Composition of Some Cuts of Texel x Bergamácia, Texel x Santa Inês and Santa Inês Lambs, Finished in Fedlot with Coffee Hull as Part of the Diet}

\begin{abstract}
Thity-six lambs, 12 crossbred Texel x Bergamácia (TB), 12 crossbred Texel x Santa Inês (TS) and 12 purebred Santa Inês (SI) lambs were individually finished in fedlot for 50 days (from 130 to 180 days of age). Each genetic group consisted of six males and six females, fed three different diets: $1=$ without coffee hulls (control); $2=$ with in nature coffee hulls; $3=$ with treated coffee hull with urea and grounded soybean grain. The animals were slaughtered at 180 days, in average. Then, the cold carcass cuts and the composition in muscle, bone and fat of the leg, shoulder and loin were evaluated. The use of the coffee hull, treated or not, did not affect the weight of the other carcass cuts and the composition of the leg, shoulder and loin. Santa Inês lambs showed smaller weight for the leg and loin muscle. The genetic group did not influence the weights of the others components, only the shoulder tended to show significant effect, indicating to be heavier for TB and TS animals. The males showed higher weights for posterior and previous arms, weights of the muscles of the shoulder, leg and loin and, also, higher bone weights of the shoulder and loin.
\end{abstract}

Key Words: sheep, crosses, carcass composition, feeding

\section{Introdução}

Geralmente, a comercialização de cordeiros é feita com base em observações no animal vivo, onde o peso do mesmo é de grande importância. Entretanto, para produtores e consumidores, é importante o conhecimento da composição percentual de diferentes partes dos animais, como por exemplo, os cortes das carcaças e a quantidade de carne nos mesmos. Segundo Huidobro \& Cañeque (1993), a proporção de cada componente é importante na avaliação comercial da carcaça. De acordo com Colomber-Rocher
(1986), o rendimento de carcaça é determinado por vários outros componentes corporais, e o valor desta depende, entre outros fatores, dos pesos relativos de seus cortes, sendo que, para melhorar esse valor, torna-se necessário conhecer aspectos relativos à nutrição, sanidade, manejo, raças e cruzamentos, e seus efeitos sobre a composição da carcaça.

No Brasil, registra-se baixo consumo da carne ovina, que está relacionado, principalmente, à baixa qualidade do produto colocado à venda. Na maioria dos mercados, o excesso de gordura é o fator que mais afeta a quantidade de carne comercializável de

\footnotetext{
1 Desenvolvido no Setor de Ovinos do Departamento de Zootecnia da Universidade Federal de Lavras - Financiado pela Fapemig.

2 Profa Adj. DZO - FCA - Faculdades Integradas Federais de Diamantina - FAFEID. E.mail: ifurusho@fafeod.br

3 Prof. Adj. DZO - Universidade Federal de Lavras (UFLA). E.mail: jroperez@ufla.br
} 
uma carcaça (Bonifacino et al., 1979; Kempster et al. 1987). Um dos fatores que influencia grandemente a valorização da carcaça comercializada é a composição relativa de seus cortes (Butterfield et. al., 1983). De acordo com Santos \& Perez (2000), o sistema de corte deve respeitar as quantidades relativas de músculo, osso e gordura, e a facilidade de uso pelo consumidor.

Os consumidores consideram importante a composição em osso, músculo e gordura, pois, devido à preocupação com a saúde, procuram adquirir um produto que contenha mais músculo e menos gordura e osso. Entretanto, não somente para o consumidor, como também para o produtor, o conhecimento da composição da carcaça e de seus cortes é fundamental para colocar no mercado produtos de qualidade que tragam maior retorno e melhor valorização dos mesmos.

As regiões corporais de cordeiros apresentam desenvolvimentos distintos segundo o grupo genético e o sexo (Arnold et al., 1997; Oliveira et al., 1998; Pires et al., 2000). A nutrição é relatada em recentes pesquisas como um dos pontos mais importantes na distribuição dos pesos relativos dos diferentes componentes da carcaça (Osório et al., 1995; Rohr \& Daenicke, 1984).

O cruzamento de uma raça de baixo potencial para produção de carne com raças especializadas para este propósito é uma alternativa para melhorar o rendimento de carcaça e obter cortes com adequada proporção de músculo, osso e gordura (Figueiró, 1979). A raça Texel tem merecido atenção, por sua precocidade, prolificidade, conformação corpórea e suas excelentes características de carcaça com menor percentagem de gordura (Latif \& Owen, 1979; Bonifacino et al., 1979).

A Santa Inês representa expressiva parte do rebanho nas regiões Nordeste, Centro-oeste e Sudeste, em função do potencial para produção de carne, sendo considerada com adequada habilidade materna e prolificidade (Santos, 1986). A Bergamácia, apesar de não ser uma raça originária do Brasil, adaptou-se às variadas condições do nosso país e, hoje, é considerada uma raça nacional.

O objetivo do presente trabalho foi verificar os pesos dos cortes da carcaça e da composição em osso, músculo e gordura da paleta, perna e lombo, de cordeiros e cordeiras cruzas Texel x Bergamácia, Texel x Santa Inês e puros Santa Inês, terminados em confinamento, com casca de café in natura e tratada com uréia como parte da dieta.

\section{Material e Métodos}

O trabalho foi conduzido no Setor de Ovinocultura do Departamento de Zootecnia da Universidade Federal de Lavras. Foram utilizados um total de 36 animais, 18 machos inteiros e 18 fêmeas, de três diferentes grupos genéticos: 12 cordeiros cruzas Texel x Bergamacia; 12 cruzas Texel x Santa Inês e 12 puros Santa Inês.

Os cordeiros foram desmamados com 75 dias de idade média, permanecendo confinados em um único grupo por um período de 45 dias, alimentados com silagem de capim-napier (Pennisetum purpurium) e concentrado. Aos 120 dias de idade média, os animais foram confinados individualmente em gaiolas de 1,3 $\mathrm{m}^{2}$, onde começaram a receber as dietas experimentais, que foram compostas de silagem de capim-napier (200 g/dia) e dos diferentes concentrados oferecidos à vontade (Tabela 1): 1 = sem casca de café (controle); $2=$ contendo casca de café in natura; $3=$ contendo casca de café tratada com $4 \%$ de uréia. Para o tratamento da casca, foram utilizados $4 \%$ de uréia (p/p da matéria natural $(\mathrm{MN})$ ), diluída em $50 \%$ de água (p/v da $\mathrm{MN}$ ) e $1 \%$ (p/p da $\mathrm{MN}$ ) de grão de soja moído (GSM), sendo a casca armazenada por três dias em sacos plásticos escuros com ausência de ar. As dietas experimentais foram isoprotéicas e isocalóricas com $15 \%$ de proteína bruta e $2.415 \mathrm{kcal} / \mathrm{kg}$, valor calculado a partir do conteúdo de cada ingrediente (NRC, 1985). A composição de nutrientes na dieta foi apresentada por Garcia et al. (2000).

Foi considerado um período de 10 dias para adaptação dos animais, durante o qual os animais foram vacinados e vermifugados. O período experimental teve início aos 130 dias de idade média, permanecendo confinados por 50 dias. Os animais foram então abatidos com 180 dias de idade média.

Após o abate, foram separados e pesados o sangue, as vísceras, a pele/lã, a cabeça e os pés/ canela. As carcaças foram limpas e suspensas em ganchos, mantendo-se as articulações tarsometatarsianas a uma distância de $17 \mathrm{~cm}$, e resfriadas em câmara fria $\left(2-4^{\circ} \mathrm{C}\right)$ por um período de 24 horas. As características de carcaça foram apresentadas por Garcia et al. (2000).

Foram retirados a cauda e o pescoço da carcaça resfriada, que foi subdividida em duas metades simétricas, através de corte saginal da coluna vertebral, sendo os cortes retirados da metade esquerda.

A separação dos cortes foi realizada de acordo com 
a Figura 1, adaptada dos estudos realizados por Sañudo \& Sierra (1986), citados por Osório (1992), sendo:

- A costeleta (COS), neste experimento, é o corte que compreende desde a primeira vértebra até 13a dorsal e suas costelas correspondentes, incluindo neste corte, segundo Osório (1992), a costela de badal (1 1 à 5 a vértebra) e a costela de palo, também chamadas de chuletas de centro (6 à $13^{\mathrm{a}}$ vértebra).

- As costelas de lombo ou chuletas, neste trabalho chamadas de lombo, possuem, como base anatômica, as vértebras lombares, compreendendo da $1 \underline{a}$ à última lombar ou $1 \underline{\text { a }}$ vértebra sacra.

- A perna correspondeu à região sacral, contendo o cíngulo pélvico. $O$ corte foi realizado na altura da última vértebra lombar e primeira sacral e na articulação da tíbia com o fêmur, ou seja, o braço posterior, que contém o osso da tíbia, não fez parte desse corte.

- A paleta corresponde às regiões anatômicas do cíngulo escapular, braço e antebraço, sendo a base óssea formada pela escápula, úmero, rádio e ossos do carpo. O corte foi feito na região axilar dos músculos que unem a escápula e oúmero na parte ventral do tórax.

Tabela 1 - Composição percentual dos concentrados utilizados nas dietas experimentais (\%)

Table 1 - Percentege composition of the concentrate used in the experimental diets (\%)

\begin{tabular}{|c|c|c|c|}
\hline \multirow[t]{2}{*}{$\begin{array}{l}\text { Ingrediente } \\
\text { Ingredient }\end{array}$} & \multicolumn{3}{|c|}{$\begin{array}{c}\text { Dieta }^{1} \\
\text { Diet }\end{array}$} \\
\hline & 1 & 2 & 3 \\
\hline $\begin{array}{l}\text { Casca de café in natura } \\
\text { Coffee hull in natura }\end{array}$ & - & 15,23 & - \\
\hline $\begin{array}{l}\text { Casca de café tratada } \\
\text { Treated coffee hull }\end{array}$ & - & - & 15,27 \\
\hline $\begin{array}{l}\text { Milho desintegrado com } \\
\text { palha e sabugo } \\
\text { Ground corn with cob and husks }\end{array}$ & 31,57 & 15,23 & 15,27 \\
\hline $\begin{array}{l}\text { Milho (grão moído) } \\
\text { Corn (ground grain) }\end{array}$ & 48,72 & 51,70 & 53,23 \\
\hline $\begin{array}{l}\text { Farelo de soja } \\
\text { Soybean meal }\end{array}$ & 14,87 & 13,16 & 11,73 \\
\hline $\begin{array}{l}\text { Farinha de carne e ossos } \\
\text { Meat and bone meal }\end{array}$ & 3,15 & 3,04 & 3,05 \\
\hline $\begin{array}{l}\text { Premix mineral e vitamínico } \\
\text { Mineral and vitamin premix }\end{array}$ & 1,03 & 0,99 & 0,99 \\
\hline $\begin{array}{l}\text { Sal } \\
\text { Salt }\end{array}$ & 0,47 & 0,46 & 0,46 \\
\hline Uréia & 0,19 & 0,19 & - \\
\hline Urea & & & \\
\hline
\end{tabular}

R. Bras. Zootec., v.32, n.6, p.1999-2006, 2003 (Supl. 2)
- O baixo, que compreende o peito e a fralda, neste trabalho chamada de costela/fralda, possui como base anatômica o externo e a parte média distal das cinco primeiras costelas, juntamente com a fralda. Este corte é obtido traçando-se uma linha reta desde a borda dorsal do reto no abdômen até a ponta do externo.

A perna, o lombo e a paleta foram congelados para posterior dissecação e obtenção dos pesos do músculo, gordura e osso.

O delineamento experimental utilizado foi inteiramente casualizado, com duas repetições, sendo os tratamentos obtidos em um esquema fatorial $3 \times 3 \times 2$ (dieta, grupo genético e sexo). Os cordeiros de cada grupo, o qual continha seis animais, ou seja, de um sexo e um determinado grupo genético, foram aleatoriamente sorteados, sendo dois para cada dieta experimental.

Os dados foram analisados com o uso do programa SAS (1999). Após análises dos dados, algumas variáveis apresentaram interação tripla significativa, a qual não houve interesse prático em seu estudo, desta forma, esse tipo de variação foi incluído no resíduo. Não houve interações duplas significativas para as variáveis deste trabalho. Portanto, a influência das fontes de variação sexo, grupo genético e dieta foi analisada separadamente.

\section{Resultados e Discussão}

De acordo com os dados da Tabela 2, verifica-se que somente o peso absoluto da costela foi influenciado pelas dietas $(\mathrm{P}<0,05)$. Os cordeiros que receberam dieta com casca de café integral apresentaram peso menor $(1,86 \mathrm{~kg})$ comparado aos animais que receberam a dieta controle $(2,15 \mathrm{~kg})$. Já os animais que receberam a dieta com casca de café in natura não mostraram diferenças, em comparação às outras duas dietas $(1,99 \mathrm{~kg})$, indicando que o tratamento químico da casca de café com uréia pode propiciar alguma melhora, já que não houve diferença em comparação com a dieta controle, entretanto, no presente trabalho, não chegou a ser significativa em relação a casca não tratada. Para todos os outros cortes da carcaça, não foi observada influência da dieta. Portanto, a utilização de $15 \%$ de casca de café, tratada ou não, é viável, sem que haja alterações no desenvolvimento do animal.

A dieta não afetou a composição da paleta, do lombo e da perna. As quantidades (em peso absoluto) de osso, músculo e gordura foram semelhantes nos três cortes, independentemente da utilização da casca de café, tratada ou não. Na observação dos dados 


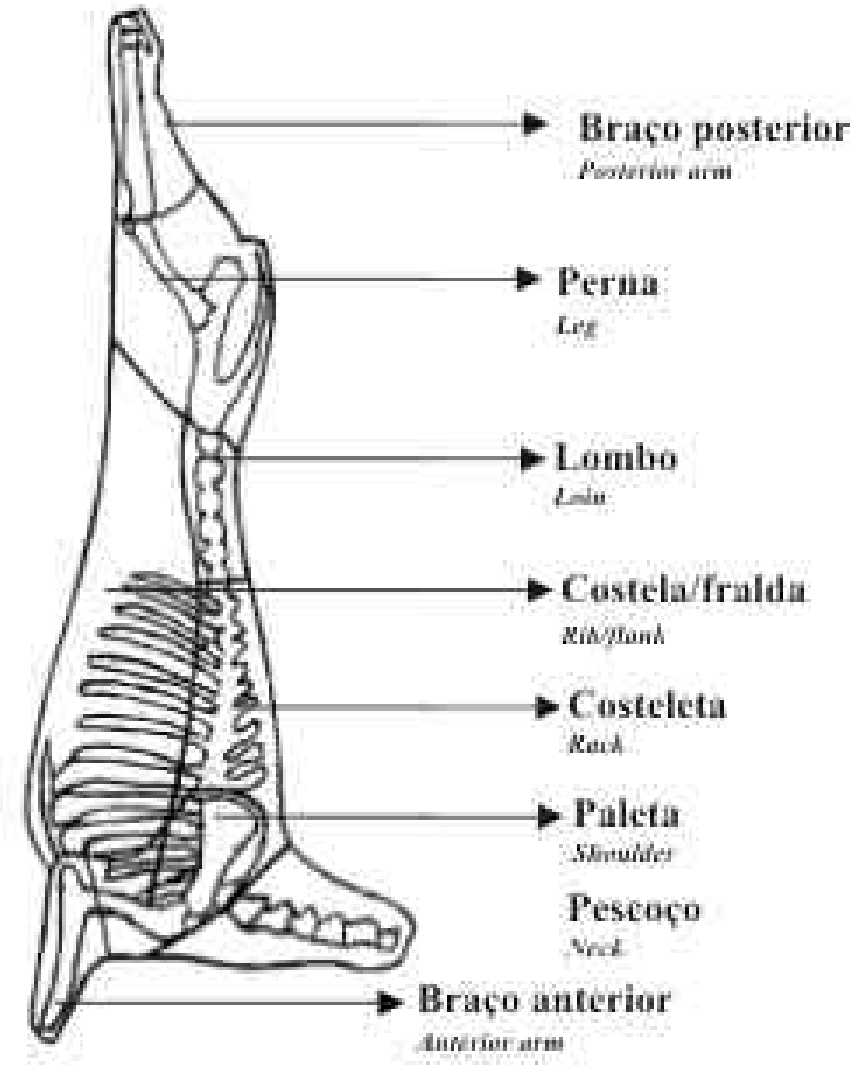

Figura 1 - Cortes efetuados na meia carcaça esquerda. (Sistema de cortes adotado pela Universidade Federal de Lavras).

Figure 1 - Cuts performed at the half left carcass (Cuts system adopted by University of Lavras).

de peso da gordura, músculo e osso, em relação ao peso do corte dos animais que consumiram a dieta contendo casca de café tratada com uréia, supõe-se que esta dieta pode vir proporcionar uma paleta com maior percentagem de músculo.

Os pesos absolutos do pescoço, braço anterior, braço posterior, costela e fralda não foram afetados pelos grupos genéticos. Portanto, a utilização de um reprodutor da raça Texel no cruzamento com ovelhas das raças Bergamácia e Santa Inês não afetou o desenvolvimento dos cordeiros, não alterando os pesos dos cortes citados acima (Tabela 3 ).

A percentagem de peso do pescoço de $6,02 \%$, em relação ao peso da carcaça fria, para os cordeiros SI, comparado à média de $4,11 \%$ dos animais cruzados, indica que os animais puros desta raça podem possuir maior proporção para este corte, provavelmente devido à própria característica racial, pois os animais da raça Santa Inês apresentam pescoços mais longos. Este fato pode ser uma desvantagem, já que o pescoço não é considerado um corte de primeira.

Para o peso absoluto da paleta, não foi observada diferença, entretanto, considerando-se que esse é um corte de importância comercial, deve-se destacar a significância ocorrida $(\mathrm{P}<0,07)$, onde os cordeiros cruzas apresentaram maiores pesos absolutos da paleta que os cordeiros Santa Inês puros, sendo que os pesos médios foram de 1,95; 2,0 e 1,41 kg, respectivamente, para TB, TS e SI. Apesar de os animais cruzas terem apresentado maior peso absoluto para a paleta, a percentagem do peso em relação ao peso da carcaça fria parece semelhante para todos os cordeiros (média de 7,46\%), provavelmente o baixo peso da carcaça fria dos animais Santa Inês, proporcionou esse resultado.

Os cordeiros cruzas TB e TS apresentaram maior peso absoluto $(\mathrm{P}<0,05)$ para lombo e perna, respectivamente, 0,82 e 3,39 $\mathrm{kg}$ para TB, e 0,88 e 3,30 para TS, sendo que os animais puros SI, apresentaram pesos de 0,63 e $2,53 \mathrm{~kg}$, respectivamente. Também houve diferenças entre os grupos genéticos para o peso do músculo da perna e do lombo. Os cordeiros cruzas TB e TS apresentaram maior peso em relação aos cordeiros Santa Inês.

Esses resultados, aliados à observação das percentagens, destacam a vantagem da utilização do cruzamento industrial, principalmente com relação ao cruzamento TS, onde verifica-se grande potencial da raça Santa Inês, na linha materna, com produção de cortes de primeira com qualidade superior, devido à maior quantidade de músculo no mesmo. Entretanto, quando os dados são observados em relação ao peso da carcaça fria, os cordeiros TB, TS e SI apresentaram, respectivamente, para o lombo, percentagem de músculo de 59,$73 ; 55,22$ e $57,37 \%$, percentagem de gordura de 17,64; 20,52 e 16,32\%, e percentagem de osso de 22,$63 ; 24,26$ e $26,31 \%$, indicando que os cordeiros cruzas não apresentaram acréscimo considerável na percentagem de músculo em relação à raça pura.

Por todos esse dados relatados, verificou-se, pela observação dos dados de percentagens, que os animais cruzas TB devem possuir menor proporção de osso, principalmente, em comparação aos animais SI. Já a gordura varia de acordo com o corte considerado, tendendo a ser maior na paleta para os cordeiros TB, maior na perna para os cordeiros SI e maior no lombo para os cordeiros TS. A gordura é o tecido mais variável da carcaça do ponto de vista quantitativo e de sua distribuição (Berg \& Butterfield, 1976); neste trabalho, 
Tabela 2 - Pesos médios e percentagem do pescoço, braço anterior e posterior, costela, fralda, paleta, perna e lombo e pesos médios e percentagem de gordura, músculo e osso da paleta, perna e lombo, com respectivos errospadrão (ep), de acordo com as dietas experimentais

Table 2 - Average weights and percentage of neck, anterior and posterior arm, rib, breast, shoulder, leg and loin and, mean weights and percentage of fat, muscle and bone of the shoulder, leg and loin, with its respective standard errors (se), according to the experimental diets

\begin{tabular}{|c|c|c|c|c|c|c|c|c|c|}
\hline \multirow{3}{*}{$\begin{array}{l}\text { Cortes } \\
\text { Cuts }\end{array}$} & & \multicolumn{8}{|c|}{$\begin{array}{c}\text { Dieta }^{4} \\
\text { Diet }^{4}\end{array}$} \\
\hline & \multicolumn{3}{|c|}{1} & \multicolumn{3}{|c|}{2} & \multicolumn{3}{|c|}{3} \\
\hline & $\begin{array}{c}\text { Peso }(\mathrm{kg}) \\
\text { Weight }(\mathrm{kg})\end{array}$ & $\begin{array}{l}\mathrm{ep} \\
\text { se }\end{array}$ & $\%$ & $\begin{array}{l}\text { Peso }(\mathrm{kg}) \\
\text { Weight }(\mathrm{kg})\end{array}$ & $\begin{array}{l}\mathrm{ep} \\
\mathrm{se}\end{array}$ & $\%$ & $\begin{array}{c}\text { Peso (kg) } \\
\text { Weight }(k g)\end{array}$ & $\begin{array}{l}\text { ep } \\
\text { se }\end{array}$ & $\%$ \\
\hline $\begin{array}{l}\text { Pescoço } \\
\text { Neck }\end{array}$ & $0,99 a$ & 0,081 & 3,98 & $1,10 \mathrm{a}$ & 0,134 & 4,93 & $1,12 \mathrm{a}$ & 0,103 & 5,15 \\
\hline $\begin{array}{l}\text { Braço anterior } \\
\text { Anterior arm }\end{array}$ & $0,33 \mathrm{a}$ & 0,021 & 1,32 & $0,35 \mathrm{a}$ & 0,024 & 1,57 & $0,33 \mathrm{a}$ & 0,019 & 1,52 \\
\hline $\begin{array}{l}\text { Braço posterior } \\
\text { Posterior arm }\end{array}$ & $0,43 \mathrm{a}$ & 0,025 & 1,73 & $0,43 \mathrm{a}$ & 0,032 & 1,93 & $0,42 \mathrm{a}$ & 0,025 & 1,93 \\
\hline $\begin{array}{l}\text { Costela } \\
\text { Rib }\end{array}$ & $2,15 \mathrm{a}$ & 0,160 & 8,65 & $1,86 b$ & 0,134 & 8,34 & $1,99 a b$ & 0,175 & 9,15 \\
\hline $\begin{array}{l}\text { Fralda/peito (baixo) } \\
\text { Breast }\end{array}$ & $2,27 \mathrm{a}$ & 0,223 & 9,13 & $2,24 \mathrm{a}$ & 0,179 & 10,05 & $2,31 \mathrm{a}$ & 0,218 & 10,62 \\
\hline $\begin{array}{l}\text { Paleta } \\
\text { Shoulder }\end{array}$ & $1,778 \mathrm{a}$ & 0,131 & 7,15 & $1,828 \mathrm{a}$ & 0,122 & 8,20 & $1,755 \mathrm{a}$ & 0,136 & 8,07 \\
\hline $\begin{array}{l}\text { Gordura } \\
\text { Fat }\end{array}$ & $0,449 a$ & 0,056 & 25,25 & $0,464 \mathrm{a}$ & 0,050 & 25,39 & $0,382 \mathrm{a}$ & 0,048 & 21,77 \\
\hline $\begin{array}{l}\text { Músculo } \\
\text { Muscle }\end{array}$ & $1,088 \mathrm{a}$ & 0,102 & 61,20 & $1,117 \mathrm{a}$ & 0,090 & 61,12 & $1,155 \mathrm{a}$ & 0,094 & 65,81 \\
\hline $\begin{array}{l}\text { Osso } \\
\text { Born }\end{array}$ & $0,241 \mathrm{a}$ & 0,011 & 13,55 & $0,247 \mathrm{a}$ & 0,018 & 13,49 & $0,218 \mathrm{a}$ & 0,012 & 12,42 \\
\hline $\begin{array}{l}\text { Perna } \\
\text { Leg }\end{array}$ & $3,212 \mathrm{a}$ & 0,185 & 12,92 & $3,045 \mathrm{a}$ & 0,167 & 13,66 & $2,965 \mathrm{a}$ & 0,210 & 13,63 \\
\hline $\begin{array}{l}\text { Gordura } \\
\text { Fat }\end{array}$ & $0,596 \mathrm{a}$ & 0,076 & 18,55 & $0,555 \mathrm{a}$ & 0,068 & 18,23 & $0,532 \mathrm{a}$ & 0,061 & 17,94 \\
\hline $\begin{array}{l}\text { Músculo } \\
\text { Muscle }\end{array}$ & $2,169 a$ & 0,051 & 67,53 & $2,089 a$ & 0,080 & 68,60 & $2,042 \mathrm{a}$ & 0,076 & 68,87 \\
\hline $\begin{array}{l}\text { Osso } \\
\text { Born }\end{array}$ & $0,447 \mathrm{a}$ & 0.029 & 13,92 & $0,401 \mathrm{a}$ & 0,033 & 13,17 & $0,391 \mathrm{a}$ & 0,040 & 13,19 \\
\hline $\begin{array}{l}\text { Lombo } \\
\text { Loin }\end{array}$ & $0,829 a$ & 0,077 & 3,33 & $0,750 \mathrm{a}$ & 0,064 & 3,36 & $0,756 a$ & 0,064 & 3,48 \\
\hline $\begin{array}{l}\text { Gordura } \\
\text { Fat }\end{array}$ & $0,158 \mathrm{a}$ & 0.022 & 19,06 & $0,134 \mathrm{a}$ & 0,013 & 17,87 & $0,137 \mathrm{a}$ & 0,015 & 18,12 \\
\hline $\begin{array}{l}\text { Músculo } \\
\text { Muscle }\end{array}$ & $0,461 \mathrm{a}$ & 0.023 & 55,61 & $0,447 \mathrm{a}$ & 0,027 & 59,60 & $0,432 \mathrm{a}$ & 0,021 & 57,14 \\
\hline $\begin{array}{l}\text { Osso } \\
\text { Born }\end{array}$ & $0,210 \mathrm{a}$ & 0.016 & 25,33 & $0,169 a$ & 0,020 & 22,53 & $0,187 \mathrm{a}$ & 0,017 & 24,73 \\
\hline
\end{tabular}

\footnotetext{
1 Percentagem em relação ao peso da carcaça fria.

1 Percentagem in relation to the cold carcass weight .

2 Percentagem em relação ao peso do corte.

2 Percentagem in relation to the cut weight.

${ }^{3}$ Médias seguidas de letras diferentes diferem $(P<0,05)$ pelo teste Tukey.

${ }^{3}$ Averages followed by different letters differ $(P<.05)$ by Tukey test.

${ }^{4} \mathrm{~A}=$ dieta controle; $\mathrm{B}=$ dieta com casca de café in natura; $\mathrm{C}=$ dieta com casca de café tratada.

${ }^{4} A=$ control diet; $B=$ diet with in natura coffee hull; $C=$ diet with treated coffee hull.
}

R. Bras. Zootec., v.32, n.6, p.1999-2006, 2003 (Supl. 2) 
Tabela 3 - Pesos médios e percentagens ${ }^{1}$ de peso do pescoço, braço anterior e posterior, costela, fralda, paleta, perna e lombo, e peso médios e percentagens ${ }^{2}$ da gordura, músculo e osso da paleta, perna e lombo, com respectivos erros-padrão (ep), de acordo com os grupos genéticos ${ }^{3}$

Table 3 - Average weights and percentage of neck, anterior and posterior arm, rib, breast, shoulder, leg and loin and, mean weights and percentage of fat, muscle and bone of the shoulder, leg and loin, with its respective standard errors (se), according to the genetic group

\begin{tabular}{|c|c|c|c|c|c|c|c|c|c|}
\hline \multirow{3}{*}{$\begin{array}{l}\text { Cortes } \\
\text { Cuts }\end{array}$} & \multicolumn{9}{|c|}{$\begin{array}{l}\text { Grupo genético } \\
\text { Genetic group }\end{array}$} \\
\hline & \multicolumn{3}{|c|}{$\mathrm{TB}$} & \multicolumn{3}{|c|}{$\mathrm{TS}$} & \multicolumn{3}{|c|}{ SI } \\
\hline & $\begin{array}{l}\text { Peso }(\mathrm{kg}) \\
\text { Weight }(\mathrm{kg})\end{array}$ & $\begin{array}{l}\text { ep } \\
\text { se }\end{array}$ & $\%$ & $\begin{array}{l}\text { Peso }(\mathrm{kg}) \\
\text { Weight }(\mathrm{kg})\end{array}$ & $\begin{array}{l}\mathrm{ep} \\
\text { se }\end{array}$ & $\%$ & $\begin{array}{l}\text { Peso }(\mathrm{kg}) \\
\text { Weight }(\mathrm{kg})\end{array}$ & $\begin{array}{l}\text { ep } \\
\text { se }\end{array}$ & $\%$ \\
\hline $\begin{array}{l}\text { Pescoço } \\
\text { Neck }\end{array}$ & $1,05 \mathrm{a}$ & 0,109 & 4,02 & $1,00 \mathrm{a}$ & 0,086 & 4,21 & $1,15 \mathrm{a}$ & 0,125 & 6,02 \\
\hline $\begin{array}{l}\text { Braço anterior } \\
\text { Anterior arm }\end{array}$ & $0,33 \mathrm{a}$ & 0,021 & 1,26 & $0,34 \mathrm{a}$ & 0,019 & 1,43 & $0,34 \mathrm{a}$ & 0,023 & 1,78 \\
\hline $\begin{array}{l}\text { Braço posterior } \\
\text { Posterior arm }\end{array}$ & $0,42 \mathrm{a}$ & 0,030 & 1,61 & $0,42 \mathrm{a}$ & 0,026 & 1,77 & $0,43 \mathrm{a}$ & 0,024 & 2,25 \\
\hline $\begin{array}{l}\text { Costela } \\
\text { Rib }\end{array}$ & $2,02 \mathrm{a}$ & 0,158 & 7,74 & $1,98 \mathrm{a}$ & 0,177 & 8,34 & $1,99 \mathrm{a}$ & 0,111 & 10,42 \\
\hline $\begin{array}{l}\text { Fralda/peito (baixo) } \\
\text { Breast }\end{array}$ & $2,27 \mathrm{a}$ & 0,192 & 8,70 & $2,39 \mathrm{a}$ & 0,219 & 10,07 & $2,19 \mathrm{a}$ & 0,106 & 11,47 \\
\hline $\begin{array}{l}\text { Paleta } \\
\text { Shoulder }\end{array}$ & $1,946 \mathrm{a}$ & 0,107 & 7,46 & $1,999 \mathrm{a}$ & 0,119 & 8,42 & $1,415 \mathrm{a}$ & 0,081 & 7,41 \\
\hline $\begin{array}{l}\text { Gordura } \\
\text { Fat }\end{array}$ & $0,519 a$ & 0,060 & 26,67 & $0,438 \mathrm{a}$ & 0,041 & 21,91 & $0,337 \mathrm{a}$ & 0,045 & 23,86 \\
\hline $\begin{array}{l}\text { Músculo } \\
\text { Muscle }\end{array}$ & $1,181 \mathrm{a}$ & 0,072 & 60,69 & $1,319 \mathrm{a}$ & 0,095 & 65,98 & $0,861 \mathrm{a}$ & 0,081 & 60,85 \\
\hline $\begin{array}{l}\text { Osso } \\
\text { Bone }\end{array}$ & $0,246 \mathrm{a}$ & 0,023 & 12,64 & $0,242 \mathrm{a}$ & 0,019 & 12,11 & $0,217 \mathrm{a}$ & 0,020 & 15,33 \\
\hline $\begin{array}{l}\text { Perna } \\
\text { Leg }\end{array}$ & $3,390 \mathrm{a}$ & 0,160 & 12,99 & $3,305 \mathrm{a}$ & 0,182 & 13,93 & $2,526 \mathrm{~b}$ & 0,113 & 13,23 \\
\hline $\begin{array}{l}\text { Gordura } \\
\text { Fat }\end{array}$ & $0,626 \mathrm{a}$ & 0,085 & 18,47 & $0,572 \mathrm{a}$ & 0,063 & 17,31 & $0,484 \mathrm{a}$ & 0,042 & 19,16 \\
\hline $\begin{array}{l}\text { Músculo } \\
\text { Muscle }\end{array}$ & $2,316 \mathrm{a}$ & 0,119 & 68,32 & $2,307 \mathrm{a}$ & 0,129 & 69,80 & $1,677 \mathrm{~b}$ & 0,116 & 66,39 \\
\hline $\begin{array}{l}\text { Osso } \\
\text { Bone }\end{array}$ & $0,448 \mathrm{a}$ & 0,045 & 13,21 & $0,426 \mathrm{a}$ & 0,037 & 12,89 & $0,365 \mathrm{a}$ & 0,030 & 14,45 \\
\hline $\begin{array}{l}\text { Lombo } \\
\text { Loin }\end{array}$ & $0,822 \mathrm{a}$ & 0,053 & 3,15 & $0,882 \mathrm{a}$ & 0,068 & 3,72 & $0,631 \mathrm{~b}$ & 0,048 & 3,30 \\
\hline $\begin{array}{l}\text { Gordura } \\
\text { Fat }\end{array}$ & $0,145 \mathrm{a}$ & 0,018 & 17,64 & $0,181 \mathrm{a}$ & 0,029 & 20,52 & $0,103 \mathrm{a}$ & 0,022 & 16,32 \\
\hline $\begin{array}{l}\text { Músculo } \\
\text { Muscle }\end{array}$ & $0,491 \mathrm{a}$ & 0,043 & 59,73 & $0,487 \mathrm{a}$ & 0,037 & 55,22 & $0,362 \mathrm{~b}$ & 0,029 & 57,37 \\
\hline $\begin{array}{l}\text { Osso } \\
\text { Bone }\end{array}$ & $0,186 \mathrm{a}$ & 0,024 & 22,63 & $0,214 \mathrm{a}$ & 0,033 & 24,26 & $0,166 \mathrm{a}$ & 0,034 & 26,31 \\
\hline
\end{tabular}

${ }_{1}^{1}$ Percentagem em relação ao peso da carcaça fria.

1 Percentagem in relation to the cold carcass weight.

2 Percentagem em relação ao peso do corte.

2 Percentagem in relation to the cut weight.

${ }^{3}$ Médias seguidas de letras diferentes nas linhas diferem $(P<0,05)$ pelo teste Tukey.

${ }^{3}$ Averages followed by different letters differ $(P<.05)$ by Tukey test.

4 TB = Texel x Bergamácia; TS = Texel x Santa Inês; SI = Santa Inês puro.

${ }^{4} T B=$ Texel $\times$ Bergamácia; TS = Texel $\times$ Santa Inês; SI = purebred Santa Inês.

R. Bras. Zootec., v.32, n.6, p.1999-2006, 2003 (Supl. 2) 
verificou-se que o grupo genético influenciou a deposição da gordura nos diferentes cortes da carcaça.

De acordo com os dados da Tabela 3, o braço posterior e o braço anterior não foram diferentes, mas foi observada pequena diferença, em nível de $6 \%$, entre machos e fêmeas. Considerando essa diferença, os machos foram superiores às fêmeas.

Para os pesos do pescoço, da costela, fralda/

Tabela 4 - Pesos médios e percentagens ${ }^{1}$ de peso do pescoço, braço anterior e posterior, costela, fralda, paleta, perna e lombo, e pesos médios e percentagens ${ }^{2}$ de gordura, músculo e osso da paleta, perna e lombo, com respectivos erros-padrão (ep), de acordo com o sexo ${ }^{1}$

Table 4 - Average weights and percentage of neck, anterior and posterior arm, rib, breast, shoulder, leg and loin and, mean weights and percentage of fat, muscle and bone of the shoulder, leg and loin, with its respective standard errors (se), according to the sex

\begin{tabular}{|c|c|c|c|c|c|c|}
\hline \multirow{5}{*}{$\begin{array}{l}\text { Cortes } \\
\text { Cuts }\end{array}$} & \multicolumn{6}{|c|}{$\begin{array}{l}\text { Sexo } \\
\text { Sex }\end{array}$} \\
\hline & \multirow{2}{*}{\multicolumn{3}{|c|}{$\begin{array}{c}\text { Machos } \\
\text { Males }\end{array}$}} & \multirow{2}{*}{\multicolumn{3}{|c|}{$\begin{array}{l}\text { Fêmeas } \\
\text { Female }\end{array}$}} \\
\hline & & & & & & \\
\hline & \multirow{2}{*}{$\begin{array}{c}\text { Peso (kg) } \\
\text { Weight (kg) }\end{array}$} & \multirow{2}{*}{$\begin{array}{l}\text { ep } \\
\text { se }\end{array}$} & \multirow[t]{2}{*}{$\%$} & \multirow{2}{*}{$\begin{array}{c}\text { Peso }(\mathrm{kg}) \\
\text { Weight }(\mathrm{kg})\end{array}$} & \multirow{2}{*}{$\begin{array}{c}\text { ep } \\
\text { se }\end{array}$} & \multirow[t]{2}{*}{$\%$} \\
\hline & & & & & & \\
\hline Pescoço & $1,15 \mathrm{a}$ & 0,109 & 4,64 & $0,99 a$ & 0,038 & 4,75 \\
\hline \multicolumn{7}{|l|}{ Neck } \\
\hline Braço anterior & $0,36 \mathrm{a}$ & 0,016 & 1,45 & $0,31 \mathrm{~b}$ & 0,010 & 1,49 \\
\hline \multicolumn{7}{|l|}{ Anterior arm } \\
\hline Braço posterior & $0,45 \mathrm{a}$ & 0,021 & 1,82 & $0,40 \mathrm{~b}$ & 0,016 & 1,92 \\
\hline \multicolumn{7}{|l|}{ Posterior arm } \\
\hline Costela & $2,05 \mathrm{a}$ & 0,155 & 8,28 & $1,94 \mathrm{a}$ & 0,085 & 9,30 \\
\hline \multicolumn{7}{|l|}{$R i b$} \\
\hline Fralda/peito (baixo) & $2,25 \mathrm{a}$ & 0,185 & 9,08 & $2,31 \mathrm{a}$ & 0,138 & 11,07 \\
\hline \multicolumn{7}{|l|}{ Breast } \\
\hline Paleta & $2,034 \mathrm{a}$ & 0,105 & 8,21 & $1,536 \mathrm{a}$ & 0,076 & 7,36 \\
\hline \multicolumn{7}{|l|}{ Shoulder } \\
\hline Gordura & $0,477 \mathrm{a}$ & 0,046 & 23,45 & $0,387 \mathrm{a}$ & 0,042 & 25,19 \\
\hline \multicolumn{7}{|l|}{ Fat } \\
\hline Músculo & $1,293 \mathrm{a}$ & 0,093 & 63,57 & $0,948 b$ & 0,074 & 61,72 \\
\hline \multicolumn{7}{|l|}{ Muscle } \\
\hline Osso & $0,264 \mathrm{a}$ & 0,015 & 12,98 & $0,201 b$ & 0,008 & 13,09 \\
\hline \multicolumn{7}{|l|}{ Bone } \\
\hline Perna & $3,367 \mathrm{a}$ & 0,167 & 13,59 & $2,771 \mathrm{a}$ & 0,119 & 13,28 \\
\hline \multicolumn{7}{|l|}{ Leg } \\
\hline Gordura & $0,623 \mathrm{a}$ & 0,064 & 18,50 & $0,498 \mathrm{a}$ & 0,034 & 17,97 \\
\hline \multicolumn{7}{|l|}{ Fat } \\
\hline Músculo & $2,285 \mathrm{a}$ & 0,119 & 67,87 & $1,906 \mathrm{~b}$ & 0,131 & 68,79 \\
\hline \multicolumn{7}{|l|}{ Muscle } \\
\hline Osso & $0,459 a$ & 0,031 & 13,63 & $0,367 \mathrm{a}$ & 0,025 & 13,24 \\
\hline \multicolumn{7}{|l|}{ Bone } \\
\hline Lombo & $0,903 \mathrm{a}$ & 0,059 & 3,64 & $0,653 \mathrm{a}$ & 0,047 & 3,13 \\
\hline \multicolumn{7}{|l|}{ Loin } \\
\hline Gordura & $0,167 \mathrm{a}$ & 0,022 & 18,49 & $0,119 a$ & 0,017 & 18,22 \\
\hline \multicolumn{7}{|l|}{ Fat } \\
\hline Músculo & $0,507 \mathrm{a}$ & 0,031 & 59,15 & $0,386 b$ & 0,026 & 59,11 \\
\hline \multicolumn{7}{|l|}{ Muscle } \\
\hline Osso & $0,229 \mathrm{a}$ & 0,015 & 25,36 & $0,148 b$ & 0,035 & 22,67 \\
\hline Bone & & & & & & \\
\hline
\end{tabular}

1 Percentagem em relação ao peso da carcaça fria.

${ }_{1}^{1}$ Percentagem in relation to the cold carcass weight.

2 Percentagem em relação ao peso do corte.

2 Percentagem in relation to the cut weight.

3 Médias seguidas de letras diferentes nas linhas diferem $(P<0,05)$ pelo teste $F$.

${ }^{3}$ Averages followed by different letters differ $(P<.05)$ by $F$ test.

R. Bras. Zootec., v.32, n.6, p.1999-2006, 2003 (Supl. 2) 
peito, paleta, lombo e pernil, não houve diferenças entre os sexos.

As percentagens de peso do braço posterior e anterior, pescoço, costela e fralda/peito, em relação ao peso da carcaça fria das fêmeas, sugerem que as fêmeas podem ter proporções superiores comparadas aos machos. Isso pode ser explicado pelo fato de as fêmeas depositarem maior quantidade de gordura na carcaça e, conseqüentemente, nesses cortes.

Observou-se que os machos apresentaram maiores $(\mathrm{P}<0,05)$ pesos absolutos para o músculo da paleta, da perna e do lombo e, ainda, maior peso absoluto do osso da paleta e do lombo (Tabela 3). Os dados de percentagem sugerem que as fêmeas podem apresentar maiores proporções de gordura na paleta e os machos, maior proporção de osso no lombo.

\section{Conclusões}

A utilização de $15 \%$ de casca de café, tratada ou não com uréia e grão de soja moído, em dietas para cordeiros terminados em confinamento, não afetou de forma significativa os pesos dos cortes da carcaça e a composição da paleta, do lombo e da perna.

A utilização de ovelhas das raças Bergamácia e Santa Inês no cruzamento industrial com reprodutor da raça Texel promoveu melhoras nos pesos dos cortes da carcaça.

Os machos apresentaram maiores pesos do osso da paleta e do lombo e maiores pesos do músculo da paleta, lombo e perna.

\section{Literatura Citada}

ARNOLD, A.M.; PERALTA, J.M.; THONNEY, M.L. Effect of testosterone on differential muscle growth and on protein and nucleic acid concentrations in muscles of growing lambs. Journal of Animal Science, v.75, n.6, p.1495-1503, 1997.

BERG, R.T.; BUTTERFIELD, R.M. New concepts of cattle growth. Sydney: Sydney University, 1976. 240p.

BONIFACINO, L.; KREMER, R.; LARROSA, J. et al. Estudio comparativo de corderos Corriedale y Corriedali X Texel. (III) Pesos al nacer, ganancias diárias y caracteristicas de las carcasas a los 109 dias. Veterinaria, v.71, p.123-131, 1979.

BUTTERFIELD, R.M.; ZAMORA, J.; JAMES, A.M. et al. Changes in body composition relative to weight and maturity in large and small strains of Australian Merino rams 1. Muscle, bone and fat. Animal Production, v.36, p.29-37, 1983.

COLOMER-ROCHER, F. Producción de canales ovinas frente al mercado común europeo. Zaragoza: Institución Fernando el Católico, 1986. 111p. (Publicación, 1052)

FIGUEIRÓ, P.R.P. Rendimento de carcaça em ovinos no Rio
Grande do Sul. In: JORNADA TÉCNICA DE PRODUÇÃO OVINA DO RIO GRANDE DO SUL, 1., 1979, Bagé. Anais... Bagé: EMBRAPA-UEPAE, 1979b. p.65-78.

GARCIA, I.F.F.; PEREZ, J.R.O.; TEIXEIRA, J.C. et al. Desempenho de cordeiros Texel x Bergamácia, Texel x Santa Inês e Santa Inês Puros, terminados em confinamento, alimentados com casca de café como parte da dieta. Revista Brasileira de Zootecnia, v.29, n.2, p.564-572, 2000.

HUIDOBRO, F.R.; CAÑEQUE, V. Producción de carne de raza Manchega. II. Conformación y estado de engarzamiento de la canal y proporción de piezas en distintos tipos comerciales. Investigación Agraria Producción y Sanidad Animal, v.8, n.3, p.233-243, 1993.

KEMPSTER, A.J.; CROSTON, D.; GUY, D.R. et al. Growth and carcass characteristics of crossbred lambs by tem sire breeds, compared at the same estimated carcass subcutaneus fat proportion. Animal Production, v.44, n.1, p.83-98, 1987.

LAFIT, M.G.A.; OWEN, E. Comparison of Texel and Suffolk sired lambs out of Finnish Landrace X Dorset Horn ewes under grazing conditions. Journal of Agricultural Science, v.93, n.1, p.235-239, 1979.

NATIONAL RESEARCH COUNCIL - NRC. Nutrient requirements of sheep. New York: National Academy Press, 1985. 99p.

ROHR, K.; DAENICKE, R. Nutritional effects on the distribution of live weight as gastrointestinal tract fill and tissue components in growing cattle. Journal of Animal Science, v.58, n.3, p.753-765, 1984.

OLIVEIRA, N.M.; OSÓRIO, J.C.S.; MONTEIRO, E.M. Produção da carne de cinco genótipos. 4. Composição regional e tecidual. Ciências Rural, v.28, n.1, p.125-129, 1998.

OSÓRIO, J.C.S. Estudio de la calidad de canales cormecializadas en el tipo ternasco segun la procedencia: bases para la mejora de dicha calidad en Brasil. Zaragoza: Universidad de Zaragoza, 1992. 335p. Tese (Doutorado em Veterinária) - Universidad de Zaragoza, 1992.

OSÓRIO, J.C.S.; SIEWERDT, F.; OSÓRIO, M.T.M. et al. Desenvolvimento alométrico das regiões corporais em ovinos. Revista da Sociedade Brasileira de Zootecnia, v.24, n.2, p.326-333, 1995.

PIRES, C.C.; SILVA, L.F.; FARINATTI, L.H.E. et al. Crescimento de cordeiros abatidos com diferentes pesos. 2. Constituintes corporais. Ciência Rural, v.30, n.5, p.869-873, 2000.

SANTOS, V.T. Ovinocultura: princípios básicos para sua instalação exploração. São Paulo: Nobel, 1986. 167p.

SANTOS, C.L.; PEREZ, J.R.O. Composição dos cortes comerciais de cordeiros Santa Inês. IN: ENCONTRO MINEIRO DE OVINOCULTURA, 1., 1998, Lavras. Anais... Lavras: Universidade Federal de Lavras, 2000. p.150-168.

STATISTICAL ANALYSES SYSTEM - SAS. SAS user's guide: statistics. Version 8 (TS MO). Cary: 1999.

Recebido em: 12/12/01 Aceito em: 26/06/03 